\title{
ISG15: leading a double life as a secreted molecule
}

\author{
Dusan Bogunovic $^{1}$, Stéphanie Boisson-Dupuis ${ }^{1,2}$ and Jean-Laurent Casanova ${ }^{1,2}$ \\ ISG15 is a well-known intracellular ubiquitin-like molecule involved in ISGylation. However, a recent study has revived the \\ notion first put forward two decades ago that ISG15 is also a secreted molecule. Human neutrophils, monocytes and \\ lymphocytes can release ISG15, even though this protein has no detectable signal peptide sequence. ISG15 has also been \\ found in the secretory granules of granulocytes. The mechanism underlying ISG15 secretion is unknown. Secreted ISG15 acts \\ on at least T and natural killer (NK) lymphocytes, in which it induces interferon (IFN)- $\gamma$ production. However, the mechanism \\ by which ISG15 stimulates these cells also remains unclear. ISG15 and IFN- $\gamma$ seem to define an innate circuit that operates \\ preferentially, but not exclusively, between granulocytes and NK cells. Inherited ISG15 deficiency is associated with severe \\ mycobacterial disease in both mice and humans. This infectious phenotype probably results from the lack of secreted ISG15, \\ because patients and mice with other inborn errors of IFN- $\gamma$ immunity also display mycobacterial diseases. In addition to \\ raising mechanistic issues, the studies described here pave the way for clinical studies of various aspects, ranging from the use \\ of recombinant ISG15 in patients with infectious diseases to the use of ISG15-blocking agents in patients with inflammatory \\ diseases.
}

Experimental \& Molecular Medicine (2013) 45, e18; doi:10.1038/emm.2013.36; published online 12 April 2013

Keywords: ISG15; MSMD; mycobacteria; secreted molecule

ISG15 was first described in 1979, by Peter Lengyel and colleagues, as a $14.5 \mathrm{kDa}$ protein. ${ }^{1}$ In 1984 , a group led by Ernest Knight $\mathrm{Jr}^{2}$ purified this protein, which they referred to as the $15 \mathrm{kDa}$ protein induced by IFN, both from human Daudi cells and Madin-Darby bovine kidney cells. Two years later, the same group cloned the complementary DNA encoding this protein from IFN- $\beta$-treated human Daudi cells. $^{3}$ The resemblance between ISG15 and ubiquitin was first revealed in 1987. ${ }^{4}$ ISG15 consists of two domains, an $\mathrm{N}$-terminal and a C-terminal domain, resembling those of ubiquitin in terms of both sequence and three-dimensional organization $^{5}$ (Figure 1). Upon synthesis, eight amino acids are immediately cleaved from the C-terminal domain of ISG15, to yield the mature form of ISG15. ${ }^{6}$ Following cleavage, a fraction of the mature ISG15 pool is covalently attached to the lysine residues of target proteins by an E1-E2E3 enzyme cascade, in a process called ISGylation. ${ }^{5}$ ISGylation has been studied in great detail biochemically and has been reviewed elsewhere. ${ }^{5,7-11}$ Unlike ubiquitin, which first emerged in yeasts, the earliest ortholog of ISG15 is found in vertebrates. The human and bovine ubiquitin sequences are 100\% identical $^{12}$ and are $100 \%$ and $96 \%$ identical to those of zebrafish and yeast, respectively. By contrast, the human and bovine ISG15 amino-acid sequences are only $67 \%$ identical $^{13}$ and human ISG15 sequence is only $37 \%$ identical to that of the more distantly related zebrafish ${ }^{5}$ (Figure 1). Thus, although ISG15 is indeed a ubiquitin-like molecule, it evolved much more recently and is much less well conserved than ubiquitin. ISG15 may have a specialized role in higher eukaryotes, or even several specialized roles in some species, and the possibility of redundancy cannot be ruled out.

In 1987, a group led by James E. Darnell and colleagues ${ }^{14,15}$ identified a $15-\mathrm{kDa}$ protein (ISG15) as being encoded by a gene, for which transcription was driven by IFN- $\beta$. They coined the term 'interferon-stimulated gene', leading to the renaming of the $15-\mathrm{kDa}$ protein as ISG15. The transcription of the gene is inducible, principally by viral agents, but also by bacterial and other agents, probably via IFN- $\alpha / \beta$ in all cases. ${ }^{5}$ Given the IFN-dependent expression of the ISG15 gene, physiological and pathological studies of ISG15 and ISGylation have explored their contribution to antiviral activity. ${ }^{5,7,16}$ Briefly, in vitro challenges with influenza A

\footnotetext{
${ }^{1}$ St Giles Laboratory of Human Genetics of Infectious Diseases, Rockefeller Branch, The Rockefeller University, New York, NY, USA and ${ }^{2}$ Laboratory of Human Genetics of Infectious Diseases, Necker Branch, Institut National de la Santé et de la Recherche Médicale, U980, University Paris Descartes, Necker Medical School, Paris, France

Correspondence: Dr D Bogunovic, St Giles Laboratory of Human Genetics of Infectious Diseases, Rockefeller Branch, The Rockefeller University, 1230 York Avenue, New York, NY 10065, USA.

E-mail: dubo210@rockefeller.edu

Received 8 February 2013; accepted 12 February 2013
} 


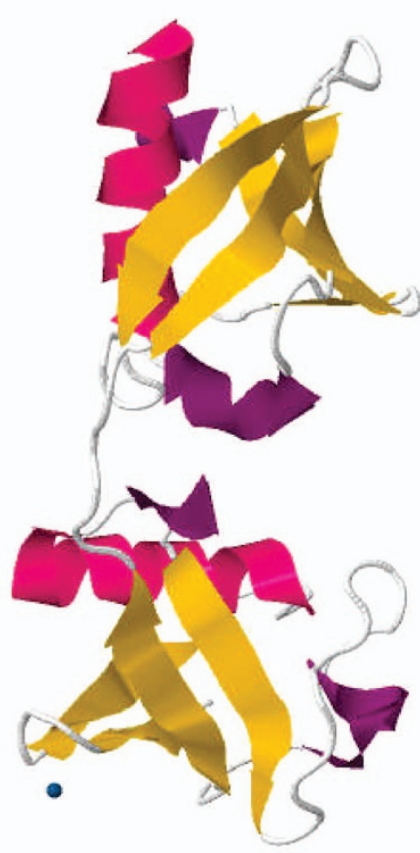

b

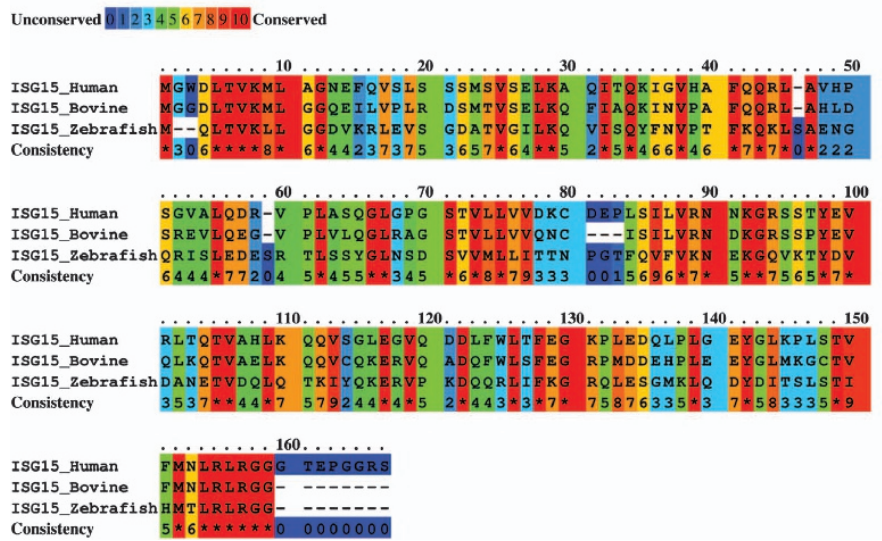

Ubiquitin

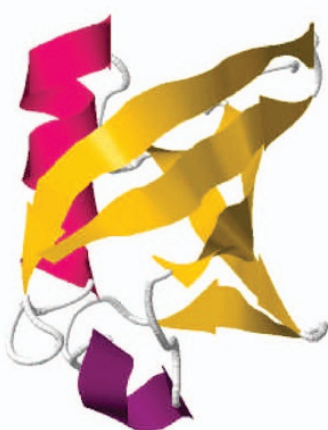

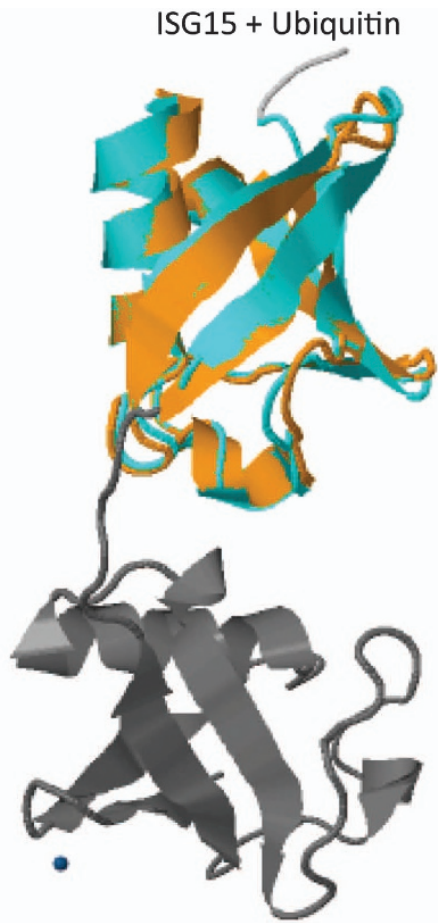

Ubiquitin

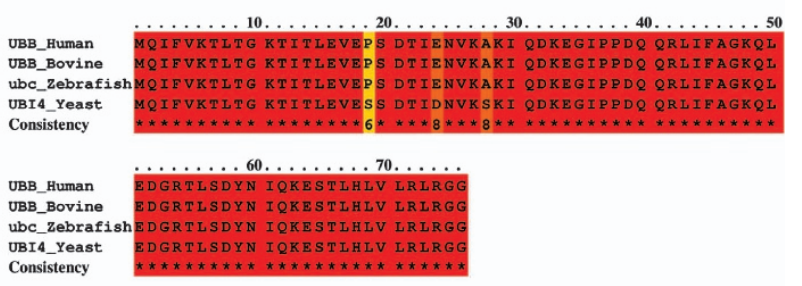

Figure 1 Tertiary structures of ISG15 and ubiquitin, alone and in combination. The structural information was obtained from the protein data bank (PDB): ubiquitin (PDB code: 1UBQ) and ISG15 (PDB code: 1Z2M). The images were obtained with PyMol software (a). Aminoacid sequence similarity analysis was performed with ISG15 molecules of human, bovine and zebrafish origin, and on ubiquitin of human, bovine, zebrafish and yeast origin. Conservation was scored with PRALINE, which assigns a score from 0 , for the least conserved alignment position, to 10 , for the most conserved alignment position (b).

rWSN strain, vesicular stomatitis virus and vaccinia virus WR strain result in the same phenotype in $I s g 15^{-/-}$murine embryonic fibroblasts and wild-type $(w t)$ murine embryonic fibroblasts. ${ }^{17-19}$ The small interfering RNA-mediated knockdown of ISG15 in wt murine cells increases the titers of dengue virus, West Nile virus and vaccinia $\mathrm{WR}$ and $\Delta \mathrm{E} 3 \mathrm{~L}$ viral stains. ${ }^{19,20}$ In human airway epithelial cells cultured in vitro, influenza A viral titers were found to increase moderately and transiently following the small interfering RNA-mediated knockdown of both ISG15 and its E1 ligase UbE1L. ${ }^{21}$ The ISG15-dependent budding of HIV has been demonstrated in $293 \mathrm{~T}$ cells. ${ }^{22}$ A couple of other reports have shown ISG15-dependent protection against Japanese encephalitis virus and Ebola VP40 VLP budding. ${ }^{23,24}$ Surprisingly, ISG15 has also been identified as a proviral molecule for hepatitis C viral replication in Huh 7.5 cells. $^{25}$ In vivo, no infectious phenotype was initially observed in Isg15-knockout mice, which display normal immunity to vesicular stomatitis virus and lymphocytic choriomeningitis viruses. ${ }^{17}$ However, Isg15 ${ }^{-/-}$mice were subsequently found to be more susceptible to influenza $\mathrm{A}$ and $\mathrm{B}$ viruses, herpes simplex virus type-1, murine gamma herpes virus 68 and Sindbis virus than their $w t$ littermates. ${ }^{18}$ Interestingly, a study carried out in 2011 suggested a role for ISG15 in immunity to Chikungunya virus infection independent of UbE1L-mediated ISGylation. ${ }^{26}$ Another study compared Isg15 ${ }^{-/-}$and Ifnar ${ }^{-/-}$ 
mice challenged with influenza B and showed that mortality was significantly higher in Ifnar ${ }^{-1-}$ animals. ${ }^{18}$ Overall, the viral infection phenotype of $\mathrm{Isg} 15^{-/-}$mice in vivo was found to be relatively mild, for seven of the nine viruses tested. ${ }^{16-18}$

The secretion of free ISG15 from cells was first reported in early 1991. ${ }^{27}$ Ernest Knight Jr and Beverly Cordova observed the slow secretion of the mature form of human ISG15 from monocytes, lymphocytes and the monocyte-derived THP-1 cell line after treatment with IFN- $\alpha / \beta$. The calculated half-life of ISG15 in THP- 1 cells was $12-15 \mathrm{~h}$, and secreted ISG15 was first detected in the medium $4-5 \mathrm{~h}$ after synthesis. ${ }^{27}$ This led the authors to refer to this process, with caution, as release rather than secretion per se. The predicted amino-acid sequence of ISG15 includes no N-terminal secretory sequence. A few months after the initial publication describing ISG15 secretion, ${ }^{27}$ the first report on its function was published. ${ }^{28}$ Human ISG15 induced the secretion of IFN- $\gamma$ from peripheral blood mononuclear cells (PBMCs). In a series of experiments based on proxy measurements of IFN- $\gamma$ (neopterin and indoleamine 2,3-dioxygenase), free ISG15 was shown to be specifically bioactive against lymphocytes. In 1995, Ernest C. Borden's group ${ }^{29}$ together with Ernest Knight Jr, confirmed that human ISG15 purified from E. coli could induce the production of IFN- $\gamma$ by PBMCs. They determined IFN- $\gamma$, interleukin (IL)-2 and IL-12 levels in the supernatants of PBMCs treated with ISG15, and noted the production of substantial amounts of IFN- $\gamma$. In the same study, they showed that the treatment of PBMCs with ISG15 induced the proliferation of NK cells and the enhanced lytic capability of lymphokine-activated killer-like cells. All of these properties of ISG15 were abolished in the presence of polyclonal antiserum from rabbits immunized with purified ISG15 or by the boiling of purified ISG15. ${ }^{29}$ Also in 1995, Ernest C. Borden and his colleagues demonstrated the presence of ISG15 in serum samples from human volunteers receiving IFN- $\beta$ injections. ${ }^{30}$
After this flurry of investigation, no further progress was made for almost two decades. Studies of free, secreted ISG15 were not followed up in either mice or humans. In 2010, a study showed that the secreted ISG15 ortholog from a fish, Sciaenops ocellatus, enhanced the respiratory burst activity, acid phosphatase activity and bactericidal activity of head-kidney macrophages. ${ }^{31}$ Our study of human patients with Mendelian susceptibility to mycobacterial diseases (MSMDs) brought us serendipitously into the ISG15 arena (Figure 2). MSMD is rare (affecting about 1 in 100000 individuals), often severe and characterized by clinical diseases due to weakly virulent mycobacteria, including environmental mycobacteria and Mycobacterium bovis Bacille Calmette-Guérin (BCG) vaccine substrains. ${ }^{32-36}$ MSMD patients are also susceptible to Salmonella and Mycobacterium tuberculosis. ${ }^{37,38}$ Known genetic etiologies of MSMD impair IFN- $\gamma$ immunity. ${ }^{39}$ Indeed, our laboratory and others have identified 17 genetic etiologies (and nine morbid genes) in patients with MSMD that impair the production of or the response to IFN- $\gamma{ }^{40-50}$ Using wholeexome sequencing, we recently identified three MSMD patients from two unrelated consanguineous families from Iran and Turkey with mutations in ISG15. ${ }^{50}$ The homozygous lesions in these two families were different, but both resulted in a loss of ISG15 production and a loss of ISGylation in all cells tested. Clinically, these patients presented only MSMD, with no unusually severe viral diseases, although their exposure to a plethora of common childhood viruses was documented. ${ }^{50}$ In vitro, viral challenges (herpes simplex-1, Sindbis, influenza and vesicular stomatitis virus) of SV-40-transformed fibroblasts have been shown to give similar results, in terms of cell survival and IFN- $\alpha$-induced protection, for ISG15 ${ }^{-/-}$ individuals and WT controls. Both clinically and in our in vitro experiments, ISG15 (and ISGylation) seems to have a redundant function in the course of naturally occurring common viral infections of childhood. The observed

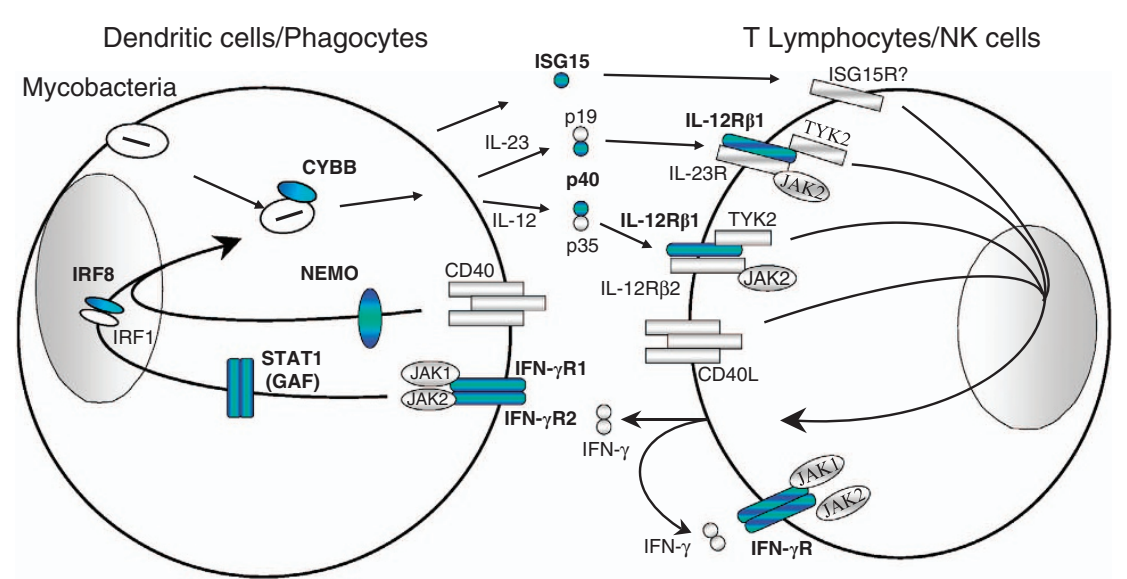

Figure 2 Inborn errors of the interleukin (IL)-12-interferon (IFN)- $\gamma$ circuit in patients with Mendelian susceptibility to mycobacterial diseases (MSMDs). Proteins for which mutations in the corresponding genes have been associated with MSMD are shown in blue. MSMDcausing mutations of ILI2B, ILI2RBI and ISG15 impair the production of IFN- $\gamma$. MSMD-causing mutations of IFNGR1, IFNGR2 and STAT1 impair the cellular response to IFN- $\gamma$. MSMD-causing mutations of NEMO impair the T-cell response and CD40-dependent production of IL-12. MSMD-causing mutations of IRF8 result in a loss of myeloid dendritic cells, and mutations of CYBB result in oxidative burst defects in macrophages. 
difference in antiviral immunity between mice and humans may reflect the difference between the experimental nature of infections in mice and the nature of infections in humans, ${ }^{32,35,36,39}$ or the limited repertoire of viruses to which these patients had been exposed at the time of study. We now need to identify more patients with ISG15 deficiency and to search for ISG15 deficiency not only in patients with MSMD, but also in patients with severe viral illnesses.

Our work on patients with inborn errors of ISG15 has confirmed that many human cell types can secrete ISG15 either in basal conditions or after IFN- $\alpha / \beta$ induction. ${ }^{50} \mathrm{We}$ have shown that ISG15 is present in steady-state neutrophils and is released by these cells upon bacterial challenge. We performed confocal microscopy to determine the subcellular distribution of ISG15 in healthy donor neutrophils. We discovered that ISG15 was present mostly in gelatinase and secretory granules but was absent from azurophilic or specific granules, suggesting an association of ISG15 with granules formed later in neutrophil development. ${ }^{50,51}$ Transcriptional profiling during human granulopoiesis has also indicated that ISG15 is induced in the later stages of neutrophil development. ${ }^{52}$ This finding was further supported by an experiment showing an absence of ISG15 detection in granulocytes from a patient with inherited granule deficiency (lacking specific, gelatinase and secretory granules). ${ }^{50}$ In vivo, these three ISG15-deficient patients displayed MSMD, probably due to the production of significantly smaller amounts of IFN- $\gamma$ compared with healthy individuals, as demonstrated in an ex vivo experiment in which whole blood was challenged with BCG and IL-12. The link between this newly identified genetic defect and IFN- $\gamma$ levels lies in the four publications from the 1990s defining secreted ISG15 as an IFN- $\gamma$-inducing molecule. ${ }^{27-30}$ IFN- $\gamma$ secretion from the blood cells of ISG $15^{-/-}$patients was restored to normal levels in the same experimental setting, by adding of human recombinant (r)ISG15 generated in HEK cells. The addition of ISG15blocking antibodies to healthy donor blood during challenge with BCG and IL-12 resulted in a decrease in IFN- $\gamma$ levels. The treatment of healthy donor PBMCs with rISG15 and IL-12 resulted in synergistic IFN- $\gamma$ production. In the same experimental setting, rISG15 $\Delta$ GG (a mutant form incapable of conjugation) also induced IFN- $\gamma$, suggesting that this activity was independent of ISGylation. Finally, we identified NK cells as the major cell type responding to ISG15 in terms of IFN- $\gamma$ production. In mice, in vivo, Philippe Gros assessed the ability of $I s g 15^{-/-}$and $w t$ littermates to fight-off low-dose aerosol infections with $M$. tuberculosis, by determining survival. Isg15 ${ }^{-/-}$mice succumbed to tuberculosis infection more rapidly than their $w t$ littermates, suggesting that ISG15 deficiency leads to mycobacterial susceptibility in both mice and humans. ${ }^{50}$ Overall, the lack of secreted ISG15 led to impaired IFN- $\gamma$ secretion, resulting in MSMD in the three patients described.

The evidence presented here raises additional questions warranting further research. ISG15 can be released by fibroblasts, monocytes, lymphocytes and neutrophils and, in some of these cell types, secretion may be induced in an IFN- $\alpha / \beta$-dependent or -independent manner. ${ }^{50}$ The mechanisms of ISG15 secretion are unknown. At least in some cell types, they probably involve a non-canonical secretory pathway independent of the ER and golgi complex, as for IL-1 $\beta$ or fibroblast growth factor 1 and $2 .^{53}$ However, the presence of ISG15 in the granules of granulocytes, the principal producers of secreted ISG15, remains puzzling. ISG15 is similar in structure to the members of a family of about 20 ubiquitin-like proteins (for example, SUMO(1-4), NEDD8, FAT10, MNSF- $\beta$ and so on.) with diverse intracellular functions. ${ }^{54}$ Ubiquitin and SUMO- 3 in humans, and MNSF- $\beta$ in murine cells, can be secreted and have been reported to have extracellular immune modulating activity. ${ }^{55-57}$ It remains unclear whether other ubiquitin-like proteins can also be secreted and/or have extracellular functions. Similarly, it is not yet clear whether the functions of secreted ubiquitin, SUMO-3 and MNSF- $\beta$ are as crucial as that of ISG15 in humans. With the exception of ubiquitin-like proteins, ISG15 does not structurally resemble any cytokines or secreted factors described to date. Hence, identifying the ISG15 cellular receptor or a potential extracellular cargo for ISG15, or both, would provide new clues to its mechanism of action and simultaneously open up new lines of research. Traditionally, the identification of a receptor has required molecular biology techniques, educated guesses as to structure/function candidates or the use of biochemical tools. However, the advent of next-generation sequencing may accelerate the discovery of this particular receptor. We have already identified MSMD patients deficient in IL-12p40 and IL-12R $\beta 1$. Likewise, it is conceivable that, in addition to ISG15-deficient individuals, there are also individuals with ISG15R mutations or deficiencies. There are still $>500$ MSMD patients with no known genetic etiology, about a quarter of whom are phenocopies of ISG15-deficient patients in terms of IFN- $\gamma$ production in whole-blood assays. Sequencing the exomes of the patients of this particular subgroup may lead to the identification of disease-causing variants of the ISG15R gene.

ISG15 can induce IFN- $\gamma$ secretion by lymphocytes, but it may well also induce the production of other cytokines by lymphocytes or other cell types. The stimulation of T cells, NK cells, B cells, NKT cells, conventional dendritic cells, plasmacytoid dendritic cells, monocytes, eosinophils, basophils and neutrophils with ISG15, followed by the collection of supernatants and multicytokine array analyses should make it possible to determine whether ISG15 has a narrow or broad cellular and/or cytokine-inducing activity. Identification of the signaling pathway responsible for IFN- $\gamma$ induction will be more laborious, requiring knockdowns of the expression of suspected key players or the use of precious preserved material from reported patients with mutations of STAT1, IL12B, IL12RB1, IFNGR1, IFNGR2, TYK2, STAT3, STAT5B, IL1ORA, IL10RB, IRF8, CD40, HOIL-1, NEMO, IKBA, MyD88, IRAK4, TLR3, UNC93B, TRIF, TRAF3 and TBK1. ${ }^{40-46,49,58-72}$ Finally, it may be worthwhile investing effort into harnessing the power 
of ISG15 in the clinical setting. Humans lacking ISG15 develop mycobacterial disease. It is conceivable that recombinant (r)ISG15, like rIFN- $\gamma$, could be used to help fight mycobacterial infection in the general population, but this hypothesis remains to be tested. IL-12 has not developed into a successful biological treatment, due to its adverse effects, and IFN- $\gamma$ is still rarely used. ${ }^{73,74}$ Regardless of the efficacy of ISG15 as an anti-infectious agent, this experiment of Nature (ISG15-deficient individuals) has already saved us years of research into the function of ISG15 in host defense in animal models. On the other side of the equation from immune deficiency lies the hyperactive immune response, involving autoimmunity, autoinflammation, hemophagocytosis, granulomatous reactions and allergy. Good health requires the achievement of a balance. Such a balance between too little and too much may also be important for ISG15, with swings to either side of the balance resulting in different diseases. Given the potent synergy between ISG15 and IL-12 in terms of IFN- $\gamma$ production by PBMCs, the blockade of ISG15, in a manner different from blocking IL-12 or IFN- $\gamma$, may result in a potent inhibition of inflammation in selected disease settings. ${ }^{75,76}$ Getting the answers to all the unresolved questions relating to the biology of secreted ISG15 in a short time span is a tall order. However, many of these answers are required before clinical applications can be considered, and in due time we can and should address them all in detail.

\section{ACKNOWLEDGEMENTS}

We would like to thank Ernest Knight Jr, Ernest C. Borden, James E. Darnell, Tamar Hermesh, Yuval Itan, Minji Byun and Laurent Abel for their thoughtful comments and advice during the preparation of this review. The work was supported in part by grants from the French National Agency for Research (ANR), the EU-grant HOMITB (HEALTH-F32008-200732), the Bill and Melinda Gates Foundation, the St Giles Foundation, the Jeffrey Modell Foundation and Talecris Biotherapeutics, the National Center for Research Resources and the National Center for Advancing Sciences (NCATS), National Institutes of Health grant number 8UL1TR000043, the National Institute of Allergy and Infectious Diseases grant number 5R37AI09598, and the Rockefeller University.

1 Farrell PJ, Broeze RJ, Lengyel P. Accumulation of an mRNA and protein in interferon-treated Ehrlich ascites tumour cells. Nature 1979; 279: 523-525.

2 Korant BD, Blomstrom DC, Jonak GJ, Knight E Jr. Interferon-induced proteins. Purification and characterization of a 15000 -dalton protein from human and bovine cells induced by interferon. J Biol Chem 1984; 259: 14835-14839.

3 Blomstrom DC, Fahey D, Kutny R, Korant BD, Knight E Jr. Molecular characterization of the interferon-induced $15-\mathrm{kDa}$ protein. Molecular cloning and nucleotide and amino acid sequence. J Biol Chem 1986; 261: 8811-8816.

4 Haas AL, Ahrens P, Bright PM, Ankel H. Interferon induces a 15-kilodalton protein exhibiting marked homology to ubiquitin. J Biol Chem 1987; 262: $11315-11323$.

5 Jeon YJ, Yoo HM, Chung $\mathrm{CH}$. ISG15 and immune diseases. Biochim Biophys Acta 2010; 1802: 485-496.

6 Knight E Jr., Fahey D, Cordova B, Hillman M, Kutny R, Reich $\mathrm{N}$ et al. A $15-\mathrm{kDa}$ interferon-induced protein is derived by $\mathrm{COOH}$-terminal processing of a 17-kDa precursor. J Biol Chem 1988; 263: 4520-4522.
7 Skaug B, Chen ZJ. Emerging role of ISG15 in antiviral immunity. Cell 2010; 143: 187-190.

8 Harty RN, Pitha PM, Okumura A. Antiviral activity of innate immune protein ISG15. J Innate Immun 2009; 1: 397-404.

9 Zhang D, Zhang DE. Interferon-stimulated gene 15 and the protein ISGylation system. J Interferon Cytokine Res 2011; 31: 119-130.

10 Durfee LA, Lyon N, Seo K, Huibregtse JM. The ISG15 conjugation system broadly targets newly synthesized proteins: implications for the antiviral function of ISG15. Mol Cell 2010; 38: 722-732.

11 Durfee LA, Huibregtse JM. Identification and validation of ISG15 target proteins. Subcell Biochem 2010; 54: 228-237.

12 Schlesinger DH, Goldstein G. Molecular conservation of 74 amino acid sequence of ubiquitin between cattle and man. Nature 1975; 255: 42304.

13 Liu C, Li X, Yao X, Kong X, Qiao W, Geng Y. Bovine ISG15: an antiviral and inducible protein in BIV infected fetal bovine lung cells. Virol J 2010; 7: 134.

14 Reich N, Evans B, Levy D, Fahey D, Knight E Jr., Darnell JE Jr. Interferoninduced transcription of a gene encoding a $15-\mathrm{kDa}$ protein depends on an upstream enhancer element. Proc Natl Acad Sci USA 1987; 84: 6394-6398.

15 Kessler DS, Levy DE, Darnell JE Jr. Two interferon-induced nuclear factors bind a single promoter element in interferon-stimulated genes. Proc Nat Acad Sci USA 1988; 85: 8521-8525.

16 Lenschow DJ. Antiviral properties of ISG15. Viruses 2010; 2 : 2154-2168.

17 Osiak A, Utermohlen O, Niendorf S, Horak I, Knobeloch KP. ISG15, an interferon-stimulated ubiquitin-like protein, is not essential for STAT1 signaling and responses against vesicular stomatitis and lymphocytic choriomeningitis virus. Mol Cell Biol 2005; 25: 6338-6345.

18 Lenschow DJ, Lai C, Frias-Staheli N, Giannakopoulos NV, Lutz A, Wolff $\mathrm{T}$ et al. IFN-stimulated gene 15 functions as a critical antiviral molecule against influenza, herpes, and Sindbis viruses. Proc Natl Acad Sci USA 2007; 104: 1371-1376.

19 Guerra S, Caceres A, Knobeloch KP, Horak I, Esteban M. Vaccinia virus E3 protein prevents the antiviral action of ISG15. PLoS Pathog 2008; 4: e1000096.

20 Dai J, Pan W, Wang P. ISG15 facilitates cellular antiviral response to dengue and West Nile virus infection in vitro. Virol J 2011; 8: 468.

21 Hsiang TY, Zhao C, Krug RM. Interferon-induced ISG15 conjugation inhibits influenza A virus gene expression and replication in human cells. J Virol 2009; 83: 5971-5977.

22 Okumura A, Lu G, Pitha-Rowe I, Pitha PM. Innate antiviral response targets HIV-1 release by the induction of ubiquitin-like protein ISG15. Proc Natl Acad Sci USA 2006; 103: 1440-1445.

23 Hsiao NW, Chen JW, Yang TC, Orloff GM, Wu YY, Lai CH et al. ISG15 over-expression inhibits replication of the Japanese encephalitis virus in human medulloblastoma cells. Antiviral Res 2010; 85: 504-511.

24 Okumura A, Pitha PM, Harty RN. ISG15 inhibits Ebola VP40 VLP budding in an L-domain-dependent manner by blocking Nedd4 ligase activity. Proc Natl Acad Sci USA 2008; 105: 3974-3979.

25 Broering R, Zhang X, Kottilil S, Trippler M, Jiang M, Lu M et al. The interferon stimulated gene 15 functions as a proviral factor for the hepatitis $C$ virus and as a regulator of the IFN response. Gut 2010; 59: 1111-1119.

26 Werneke SW, Schilte C, Rohatgi A, Monte KJ, Michault A, ArenzanaSeisdedos $\mathrm{F}$ et al. ISG15 is critical in the control of Chikungunya virus infection independent of UbE1L mediated conjugation. PLoS Pathog 2011; 7: e1002322.

27 Knight E Jr, Cordova B. IFN-induced $15-k D a$ protein is released from human lymphocytes and monocytes. J Immunol 1991; 146: 2280-2284.

28 Recht M, Borden EC, Knight E Jr. A human 15-kDa IFN-induced protein induces the secretion of IFN-gamma. J Immunol 1991; 147: 2617-2623.

29 D'Cunha J, Knight E Jr, Haas AL, Truitt RL, Borden EC. Immunoregulatory properties of ISG15, an interferon-induced cytokine. Proc Natl Acad Sci USA 1996; 93: 211-215.

30 D'Cunha J, Ramanujam S, Wagner RJ, Witt PL, Knight E Jr. Borden EC. In vitro and in vivo secretion of human ISG15, an IFN-induced immunomodulatory cytokine. J Immunol 1996; 157: 4100-4108.

31 Liu CS, Sun Y, Zhang M, Sun L. Identification and analysis of a Sciaenops ocellatus ISG15 homologue that is involved in host immune defense against bacterial infection. Fish Shellfish Immunol 2010; 29: 167-174.

32 Casanova JL, Abel L. Inborn errors of immunity to infection: the rule rather than the exception. J Exp Med 2005; 202: 197-201.

33 Casanova JL, Abel L. Genetic dissection of immunity to mycobacteria: the human model. Annu Rev Immunol 2002; 20: 581-620. 
34 Quintana-Murci L, Alcais A, Abel L, Casanova JL. Immunology in natura: clinical, epidemiological and evolutionary genetics of infectious diseases. Nat Immunol 2007; 8: 1165-1171.

35 Casanova JL, Abel L. Primary immunodeficiencies: a field in its infancy. Science 2007; 317: 617-619.

36 Alcais A, Abel L, Casanova JL. Human genetics of infectious diseases: between proof of principle and paradigm. J Clin Invest 2009; 119: 2506-2514.

37 Boisson-Dupuis S, El Baghdadi J, Parvaneh N, Bousfiha A, Bustamante J, Feinberg $\mathrm{J}$ et al. IL-12Rbetal deficiency in two of fifty children with severe tuberculosis from Iran, Morocco, and Turkey. PLoS One 2011; 6 : e18524.

38 Bustamante J, Boisson-Dupuis S, Jouanguy E, Picard C, Puel A, Abel L et al. Novel primary immunodeficiencies revealed by the investigation of paediatric infectious diseases. Curr Opin Immunol 2008; 20: 39-48.

39 Alcais A, Quintana-Murci L, Thaler DS, Schurr E, Abel L, Casanova JL. Life-threatening infectious diseases of childhood: single-gene inborn errors of immunity? Ann N Y Acad Sci 2010; 1214: 18-33.

40 Jouanguy E, Altare F, Lamhamedi S, Revy P, Emile JF, Newport M et al. Interferon-gamma-receptor deficiency in an infant with fatal bacille Calmette-Guerin infection. N Engl J Med 1996; 335: 1956-1961.

41 Newport MJ, Huxley CM, Huston S, Hawrylowicz CM, Oostra BA, Williamson $\mathrm{R}$ et al. A mutation in the interferon-gamma-receptor gene and susceptibility to mycobacterial infection. N Engl J Med 1996; 335: 1941-1949.

42 Altare F, Durandy A, Lammas D, Emile JF, Lamhamedi S, Le Deist F et al. Impairment of mycobacterial immunity in human interleukin-12 receptor deficiency. Science 1998; 280: 1432-1435.

43 Altare F, Lammas D, Revy P, Jouanguy E, Doffinger R, Lamhamedi S et al. Inherited interleukin 12 deficiency in a child with bacille Calmette-Guerin and Salmonella enteritidis disseminated infection. J Clin Invest 1998, 102: 2035-2040.

44 de Jong R, Altare F, Haagen IA, Elferink DG, Boer T, van Breda Vriesman PJ et al. Severe mycobacterial and Salmonella infections in interleukin-12 receptor-deficient patients. Science 1998; 280: 1435-1438.

45 Dorman SE, Holland SM. Mutation in the signal-transducing chain of the interferon-gamma receptor and susceptibility to mycobacterial infection. J Clin Invest 1998; 101: 2364-2369.

46 Dupuis S, Dargemont C, Fieschi C, Thomassin N, Rosenzweig S, Harris J et al. Impairment of mycobacterial but not viral immunity by a germline human STAT1 mutation. Science 2001; 293: 300-303.

47 Filipe-Santos O, Bustamante J, Haverkamp MH, Vinolo E, Ku CL, Puel A et al. X-linked susceptibility to mycobacteria is caused by mutations in NEMO impairing CD40-dependent IL-12 production. J Exp Med 2006; 203: $1745-1759$.

48 Bustamante J, Arias AA, Vogt G, Picard C, Galicia LB, Prando C et al. Germline CYBB mutations that selectively affect macrophages in kindreds with X-linked predisposition to tuberculous mycobacterial disease. Nat Immunol 2011; 12: 213-221.

49 Hambleton S, Salem S, Bustamante J, Bigley V, Boisson-Dupuis S, Azevedo $\mathrm{J}$ et al. IRF8 mutations and human dendritic-cell immunodeficiency. N Engl J Med 2011; 365: 127-138.

50 Bogunovic D, Byun M, Durfee LA, Abhyankar A, Sanal O, Mansouri D et al. Mycobacterial disease and impaired IFN-gamma immunity in humans with inherited ISG15 deficiency. Science 2012; 337: 1684-1688.

51 Borregaard N. Neutrophils, from marrow to microbes. Immunity 2010; 33: $657-670$

52 Theilgaard-Monch K, Jacobsen LC, Borup R, Rasmussen T, Bjerregaard $M D$, Nielsen FC et al. The transcriptional program of terminal granulocytic differentiation. Blood 2005; 105: 1785-1796.

53 Duitman EH, Orinska Z, Bulfone-Paus S. Mechanisms of cytokine secretion: a portfolio of distinct pathways allows flexibility in cytokine activity. Eur J Cell Biol 2011; 90: 476-483.

54 van der Veen AG, Ploegh HL. Ubiquitin-like proteins. Annu Rev Biochem 2012; 81: 323-357.

55 Majetschak M. Extracellular ubiquitin: immune modulator and endogenous opponent of damage-associated molecular pattern molecules. J Leukoc Biol 2011; 89: 205-219.

56 Hosono $\mathrm{H}$, Yokosawa $\mathrm{H}$. Small ubiquitin-related modifier is secreted and shows cytokine-like activity. Biol Pharm Bull 2008; 31: 834-837.

57 Kondoh T, Nakamura M, Nabika T, Yoshimura Y, Tanigawa Y. Ubiquitin-like polypeptide inhibits the proliferative response of T cells in vivo. Immunobiology 1999; 200: 140-149.
58 Smahi A, Courtois G, Vabres P, Yamaoka S, Heuertz S, Munnich A et al. Genomic rearrangement in NEMO impairs NF-kappaB activation and is a cause of incontinentia pigmenti. The International Incontinentia Pigmenti (IP) Consortium. Nature 2000; 405: 466-472.

59 Ferrari S, Giliani S, Insalaco A, Al-Ghonaium A, Soresina AR, Loubser $\mathrm{M}$ et al. Mutations of CD40 gene cause an autosomal recessive form of immunodeficiency with hyper IgM. Proc Natl Acad Sci USA 2001; 98: 12614-12619.

60 Courtois G, Smahi A, Reichenbach J, Doffinger R, Cancrini C, Bonnet $\mathrm{M}$ et al. A hypermorphic IkappaBalpha mutation is associated with autosomal dominant anhidrotic ectodermal dysplasia and $\mathrm{T}$ cell immunodeficiency. J Clin Invest 2003; 112: 1108-1115.

61 Kofoed EM, Hwa V, Little B, Woods KA, Buckway CK, Tsubaki J et al. Growth hormone insensitivity associated with a STAT5b mutation. N Engl J Med 2003; 349: 1139-1147.

62 Picard C, Puel A, Bonnet M, Ku CL, Bustamante J, Yang K et al. Pyogenic bacterial infections in humans with IRAK-4 deficiency. Science 2003 299: 2076-2079.

63 Casrouge A, Zhang SY, Eidenschenk C, Jouanguy E, Puel A, Yang K et al. Herpes simplex virus encephalitis in human UNC-93B deficiency. Science 2006; 314: 308-312.

64 Minegishi Y, Saito M, Morio T, Watanabe K, Agematsu K, Tsuchiya S et al. Human tyrosine kinase 2 deficiency reveals its requisite roles in multiple cytokine signals involved in innate and acquired immunity. Immunity 2006; 25: 745-755.

65 Minegishi Y, Saito M, Tsuchiya S, Tsuge I, Takada H, Hara T et al. Dominant-negative mutations in the DNA-binding domain of STAT3 cause hyper-lgE syndrome. Nature 2007; 448: 1058-1062.

66 Zhang SY, Jouanguy E, Ugolini S, Smahi A, Elain G, Romero P et al. TLR3 deficiency in patients with herpes simplex encephalitis. Science 2007; 317: 1522-1527.

67 von Bernuth H, Picard C, Jin Z, Pankla R, Xiao H, Ku CL et al. Pyogenic bacterial infections in humans with MyD88 deficiency. Science 2008; 321: 691-696.

68 Glocker EO, Kotlarz D, Boztug K, Gertz EM, Schaffer AA, Noyan F et al. Inflammatory bowel disease and mutations affecting the interleukin-10 receptor. N Engl J Med 2009; 361: 2033-2045.

69 Perez de Diego R, Sancho-Shimizu V, Lorenzo L, Puel A, Plancoulaine S, Picard $\mathrm{C}$ et al. Human TRAF3 adaptor molecule deficiency leads to impaired Toll-like receptor 3 response and susceptibility to herpes simplex encephalitis. Immunity 2010; 33: 400-411.

70 Sancho-Shimizu V, Perez de Diego R, Lorenzo L, Halwani R, Alangari A, Israelsson $\mathrm{E}$ et al. Herpes simplex encephalitis in children with autosomal recessive and dominant TRIF deficiency. J Clin Invest 2011; 121: 4889-4902.

71 Boisson B, Laplantine E, Prando C, Giliani S, Israelsson E, Xu Z et al. Immunodeficiency, autoinflammation and amylopectinosis in humans with inherited HOIL-1 and LUBAC deficiency. Nat Immunol 2012; 13: $1178-1186$.

72 Herman M, Ciancanelli M, Ou YH, Lorenzo L, Klaudel-Dreszler M, Pauwels $\mathrm{E}$ et al. Heterozygous TBK1 mutations impair TLR3 immunity and underlie herpes simplex encephalitis of childhood. J Exp Med 2012; 209: $1567-1582$.

73 Salem ML, Gillanders WE, Kadima AN, El-Naggar S, Rubinstein MP, Demcheva $\mathrm{M}$ et al. Review: novel nonviral delivery approaches for interleukin-12 protein and gene systems: curbing toxicity and enhancing adjuvant activity. J Interferon Cytokine Res 2006; 26: 593-608.

74 Gao XF, Yang ZW, Li J. Adjunctive therapy with interferon-gamma for the treatment of pulmonary tuberculosis: a systematic review. Int $\mathrm{J}$ Infect Dis 2011; 15: e594-e600.

75 Yeilding N, Szapary P, Brodmerkel C, Benson J, Plotnick M Zhou $\mathrm{H}$ et al. Development of the IL-12/23 antagonist ustekinumab in psoriasis: past, present, and future perspectives. Ann N Y Acad Sci 2011; 1222: 30-39.

76 Laws PM, Young HS. Current and emerging systemic treatment strategies for psoriasis. Drugs 2012; 72: 1867-1880.

(1) () $\odot$ This work is licensed under a Creative Commons Attribution-NonCommercial-NoDerivs 3.0 Unported License. To view a copy of this license, visit http:// creativecommons.org/licenses/by-nc-nd/3.0/ 